\title{
Artistic demonstrations by Euclidean geometry: possible in 2D but impossible in 3D
}

\section{Opinion}

The major objective of this article is to demonstrate 2D artworks that are impossible in 3D according to Euclidean Geometry. An impossible figure is defined as being a two-dimensional image that is interpreted to give the impression of some three-dimensional object that cannot exist. It was the Swedish artist Oscar Reutersvärd who in 1934 drew the impossible triangle demonstrated in Figures 1-3 by the artworks of the Denmark artist Hermann Paulsen. This object is also known as Penrose triangle that was created in 1950 independently by the British mathematician Roger Penrose. The triangle, impossible at $3 \mathrm{D}$, appears in $2 \mathrm{D}$ to be a solid object. It is made of three straight beams of square cross-section, which meet pair wise at right angles at the vertices of the triangle they form. Other impossible objects in 3D of Paulsen are presented in Figures 4-6. Figure 7, "Impossible Chess Set", and Figure 8, "Gateway to the Fourth Dimension", were painted by Sandro Del Prete, a Swiss Illusionist. By a deep observation, it becomes clear how these artworks are impossible in 3D. Figures 9-11 is additional impossible 3D artworks of the FlemishBelgian painter Jos De Mey where his face was added to the image in Figure11. Jos is known for depictions of impossible objects in a photorealistic style. And finally the artworks 12-14 by M.C.Escher, Dutch graphic artist who creates amazing 3D impossible situations. Figure 12, "Waterfall", is based on the Impossible Triangle, which is fitted three times over into the picture. Figure 13, "Ascending and Descending", demonstrates a double paradox where the figures on the outer edge appear to ascend endlessly, while the figures on the inner edge endlessly descend. Figure 14, "Belvedere" is a lithograph print showing a plausible-looking building that turns out to be impossible. For example, from the viewer's perspective, all the pillars on the first floor are the same size on both the front and back. Moreover, the pillars at the front support the backside of the top floor while the pillars at the back support the front side. In conclusion all artworks demonstrate how 2D may demonstrate impossible 3D situations that at first glance seem real in the eye of the beholder.

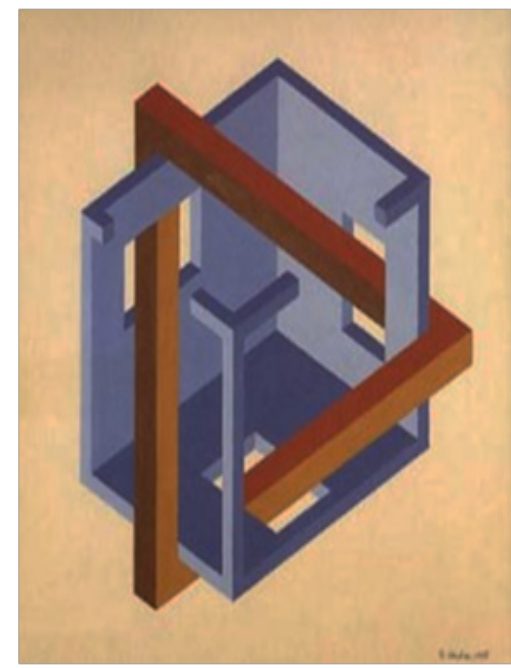

Figure I 2D artwork impossible in 3D.
Volume 4 Issue 2 - 2017

\section{Hyacinth OU}

Department of Public Health, Saudi Electronic University, Saudi Arabia

Correspondence: Hyacinth OU, Department of Public Health, Saudi Electronic University, PO Box 93499, Riyadh II 673, Saudi Arabia, Tel +966 | |2613500, Fax +966| | 2613578, Email hyacoo2000@yahoo.com

Received: May 05, 2017 | Published: August II, 2017

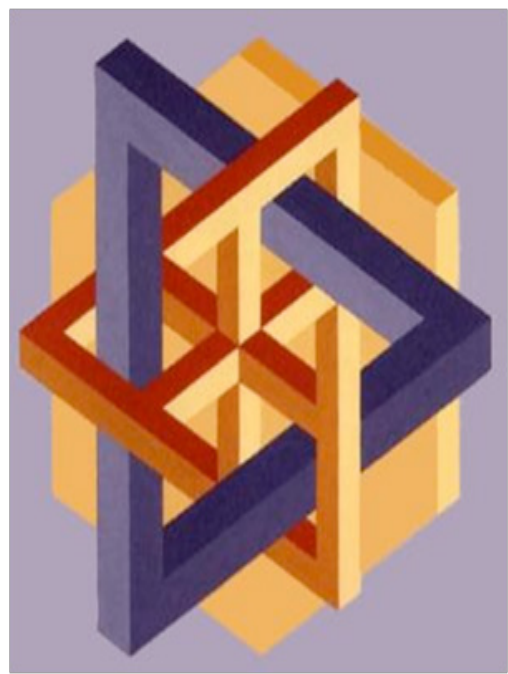

Figure 2 impossible in 3D.

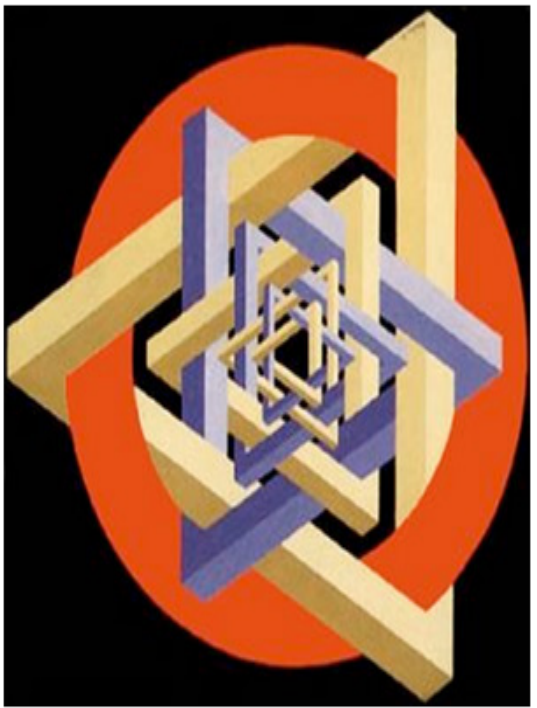

Figure 3 impossible triangle. 


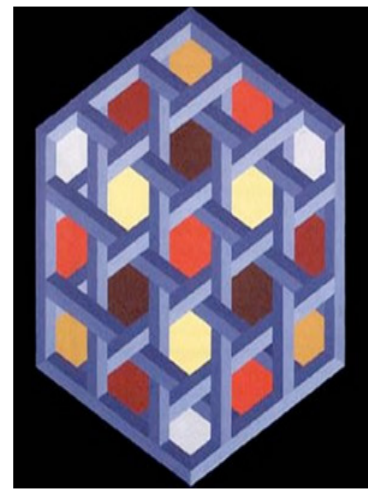

Figure 4 appears in 2D to be a solid object.

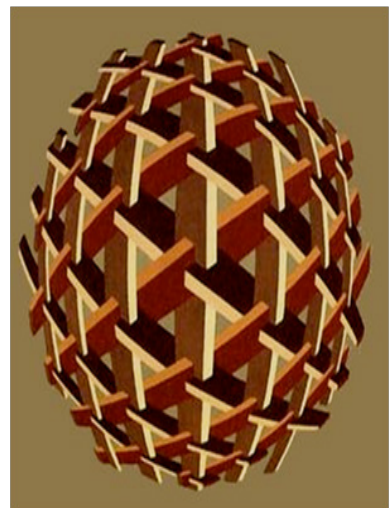

Figure 5 Other impossible objects in 3D.

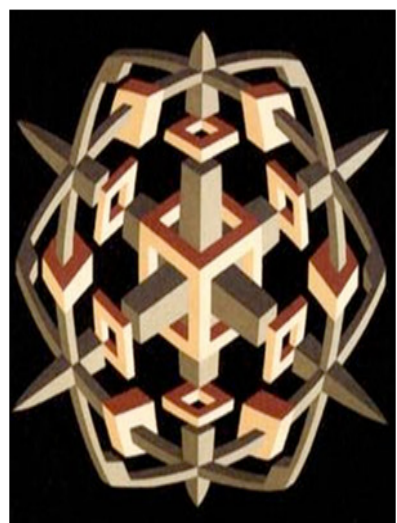

Figure 6 Three straight beams of square cross-section.

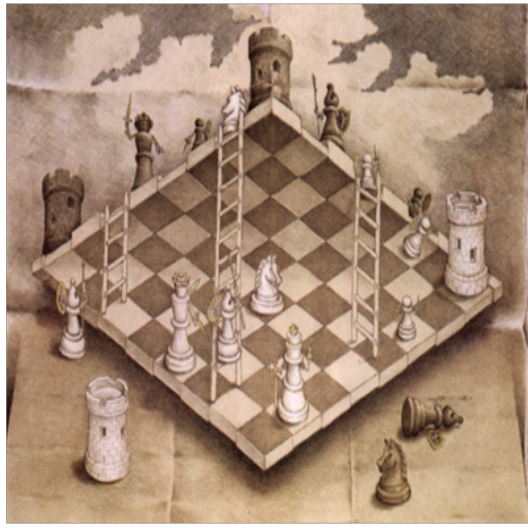

Figure 7 Impossible chess set.

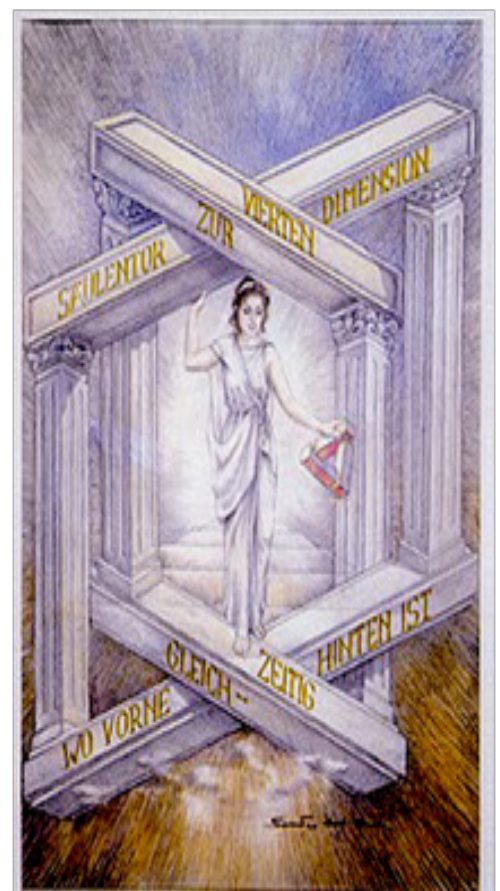

Figure 8 Gateway to the fourth dimension.

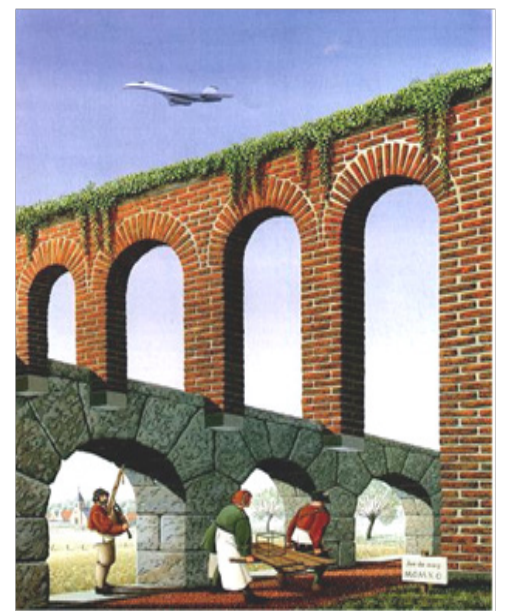

Figure 9 impossible in 3D.

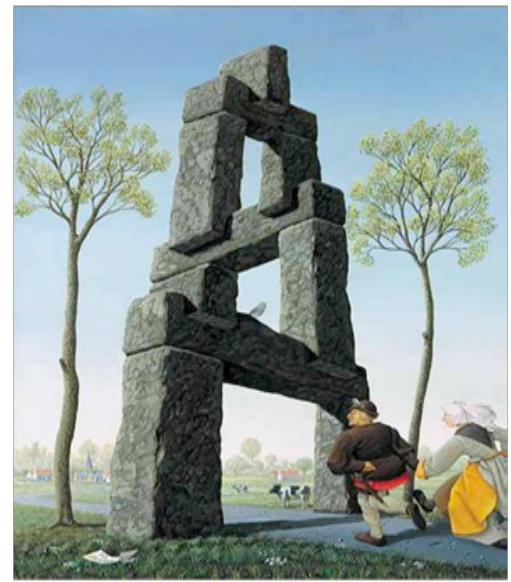

Figure 10 Additional impossible 3D. 


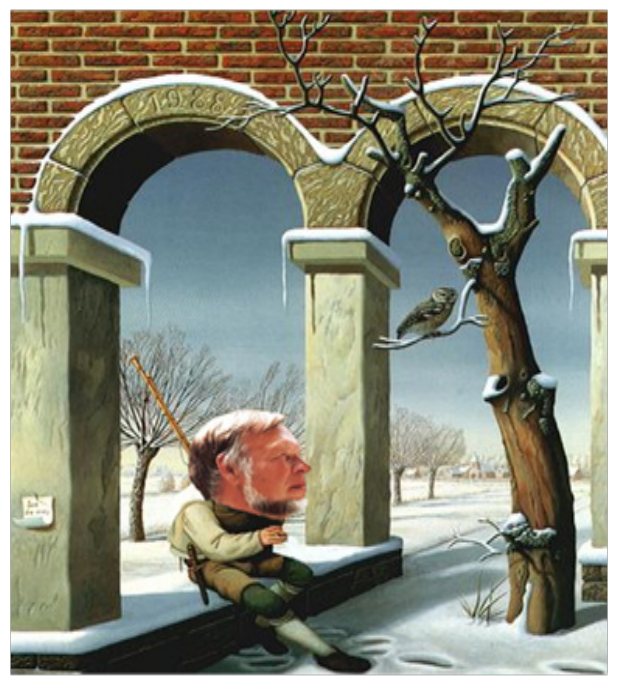

Figure I I Depictions of impossible objects in a photorealistic.

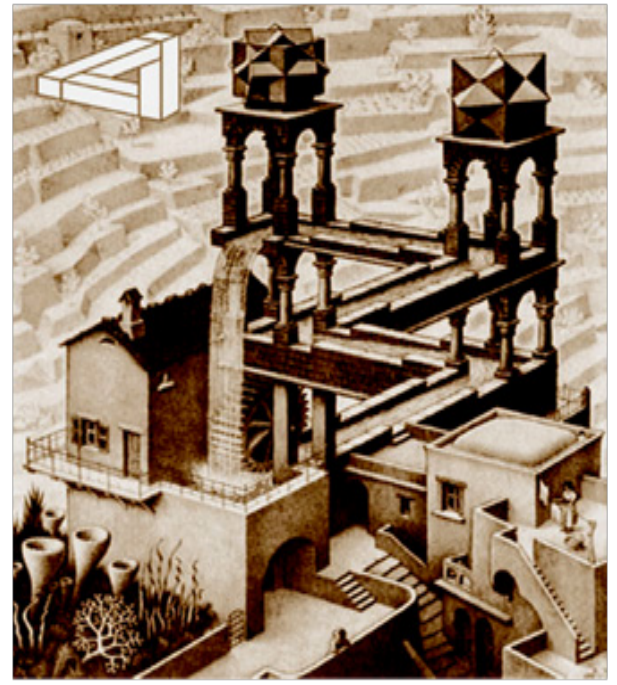

Figure 12 Impossible triangle.

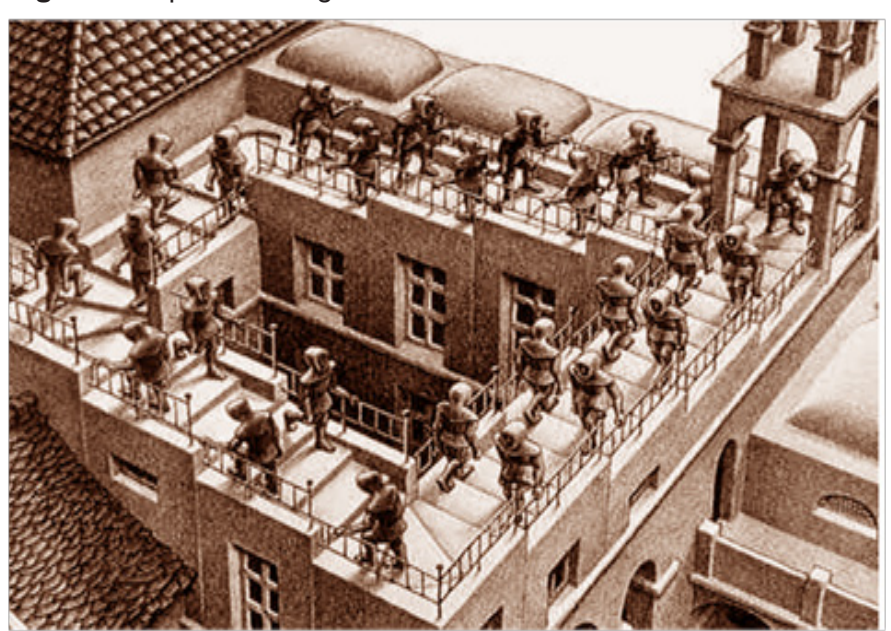

Figure 13 Double paradox.

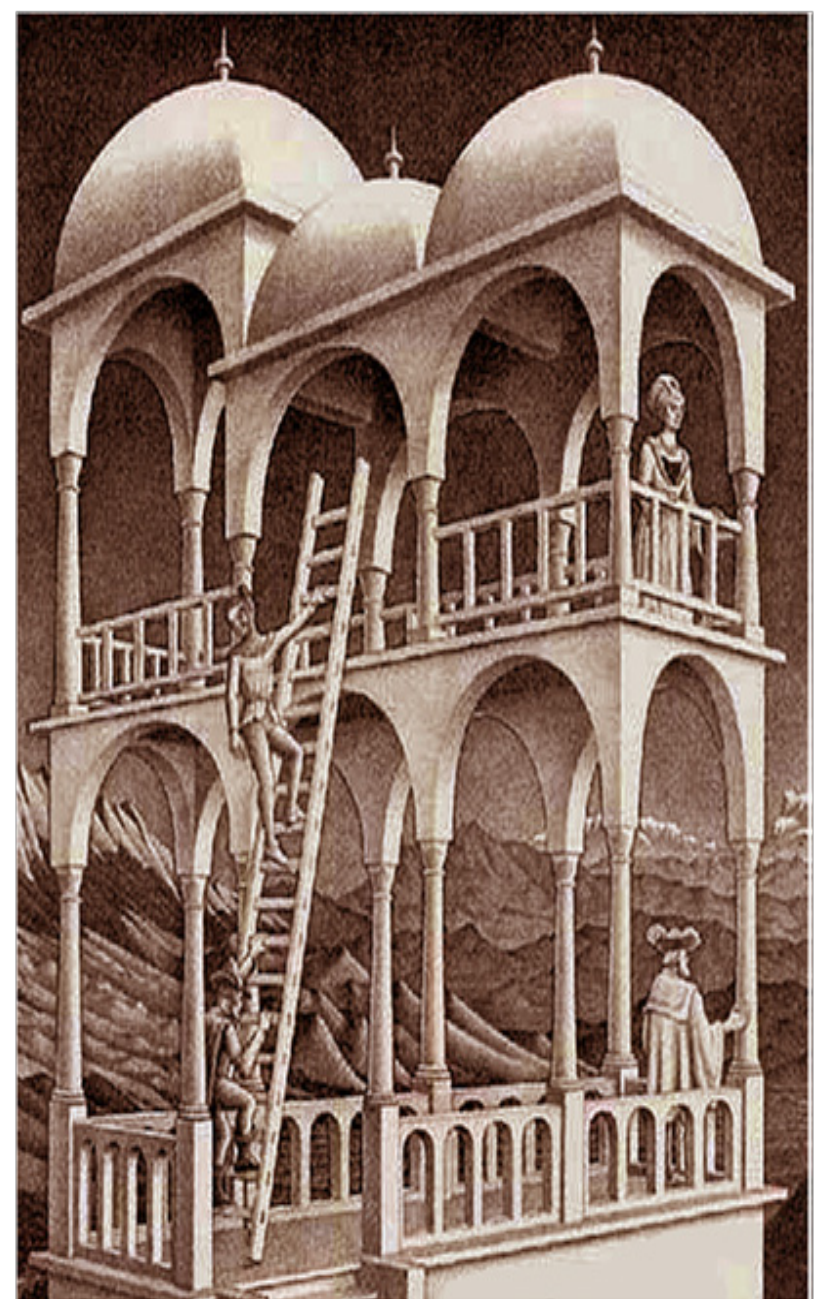

Figure I4 Plausible-looking building that turns out to be impossible.

\section{Acknowledgements}

None.

\section{Conflict of interest}

The author declares no conflict of interest. 